\title{
Game of tariffs: The impact of market concentration on international trade
}

\author{
Sławomir Kalinowski \\ Department of Microeconomics, Poznań University of Economics and \\ Business, Poznań, Poland \\ slawomir.kalinowski@ue.poznan.pl \\ ORCID 0000-0002-3945-4195
}

\begin{abstract}
The article investigates the impact of the concentration, measured by the number of firms in the exporting industry, on the tariffs and welfare generated by international exchange. The research was conducted in two dimensions. First, the model of bilateral trade exchange between two economies was tested in terms of a non-cooperative game. Nash equilibria point to the tariff rates which negatively depend on the number of firms in the exporting industry. The welfare grows with increasing competition, but its marginal value diminishes. The second perspective was the application of the Kalai-Smorodinsky bargaining solution in order to indicate the outcome of a cooperative version of the game. The cooperative solution was always a zero tariff option for symmetric market structures. If there is a more competitive exporting industry in one country, it should negotiate a tariff higher than zero, whilst a country with less competitive exporters should agree upon a zero tariff. Such an outcome of negotiations is hard to achieve from a political point of view.
\end{abstract}

Keywords: international trade, tariff rate negotiations, market structures, KalaiSmorodinsky bargaining solution.

JEL Classification: F11, L13, C71, C72

\section{INTRODUCTION}

Perfect competition in the market produces the highest volume of welfare measured by the sum of consumer surplus and profits of the operating firms. It also determines the lowest possible level of market concentration. A diminishing number of enterprises results in a decrease in welfare and the growth of concentration measures (assuming an equal market share for all firms). Competition, erasing barriers of entry, stimulates welfare growth. The same is true in the case of international trade. Eliminating or at least reducing trade barriers fertilizes global supply growth and reduces prices. This paper aims to check how the concentration in the exporting industry influences the tariff level, which is the most important trade barrier. 
In the early 1980s, the traditional approach to international trade founded on the comparative advantages of economies started to be superseded by imperfect competition models, leading to economies of scale being a major stimuli of international trade growth. The works of Krugman (1979), Dixit and Norman (1980), Ethier (1982), and others support the idea of increasing returns under monopolistic competition stimulating international trade. Other investigations have focused on the variety of market structures proceeding international trade. The asymmetry between the domestic market (monopoly) and competitive exporters of the same product was tested in the context of protecting the market power of the domestic producer (Bhagwati 1965). The study showed that it is better for the welfare to use tariffs instead of quotas. Another research study combined the sole domestic producer with the monopolistic exporter in a duopoly (Krishna 1984), which proved that voluntary export restrictions may improve the profits of both parties.

The importance of negotiations opened the gate for game theory as a tool for enhancing the research methodology in international trade. The possibility of choosing a cooperative or non-cooperative version of the game was exploited in a study by Copeland (1990), who developed a two-stage game. First, governments negotiate the chosen barrier's level. Afterwards, they estimate the levels of other barriers in a non-cooperative game. The outcome was that benefits from a negotiated reduction of the barrier can be restricted by informational restraints and transaction costs. Another study, important for this article, confronts the Nash equilibrium of a two-player game with a cooperative Nash bargaining solution in international trade (Harrison, Radstrom, 1991). Using the Nash equilibrium as a status quo point in the cooperative game and a general equilibrium model as a tool to calculate welfares, the authors verified the feasibility of trade agreements between the USA and Canada, or the USA, EU, and Japan.

The payoff function in theoretical game studies on international trade is defined variously. The most common approach is to take the welfare function compounded of consumer surplus, producer surplus, and fiscal revenues from tariffs. Ederington added revenues from the production tax of a domestic firm in order to investigate the link between domestic economic policy and foreign trade policy (Ederington, 2003). The study proved that "nonlinkage is more desirable if there is a positive probability that a country will erroneously believe that its trading partner is cheating on the agreement (triggering an unnecessary punishment phase). In contrast, linkage is more desirable if there is a positive probability that cheating will go unnoticed" (Ederington, 2003, 305). Consumer and producer surpluses supplemented by revenues from tariffs were also exploited in another study (Zhang, Xue, Zu, 2013). The authors, using this welfare function, proved that starting from any free trade network or even empty network, there is a farsightedly improving path leading to global free trade.

An alternative approach is to define the utility as a function of the quantity of the exported good and quantity of the imported one, compounded by domestic production and brought from abroad (Zotti, Lucke 2014). The authors built a model of a simple, small, and open economy, with one competitive and one oligopolistic sector. Through optimal quantities of both goods, they revealed that the utility function depended on the level of the tariff. Therefore, the optimal tariff rate could be found. This depends on the number of firms in the industry ( $\mathrm{n}$ ). The higher $\mathrm{n}$ is, the lower the optimal tariff rate (Zotti, Lucke, 2014, 412).

The purpose of this paper is to find an answer to the question of whether the concentration of the exporter's markets influences the welfare from foreign trade and the level of custom tariffs. The model was founded on welfare functions summing the benefits of each economy participating in international exchange: profits of the exporters, consumer surplus, and the budgetary revenues from customs duty.

The article consists of four chapters. Introduction presents the studies in the field of research. Second chapter is the presentation of the model founded on the Cournot type of competition. Then there is the 
chapter devoted to indication of the non-cooperative and cooperative solutions of the game. The article is closed with the conclusions.

\section{MODEL PRESENTATION}

Classic trade theory proves that free international exchange stimulates welfare growth. The lower the tariffs are, the higher the benefits are for the economy. In this article, this conclusion is revised in a twostage strategic game. First, governments decide upon tariffs. Afterwards, firms decide on the output under Cournot-type competition. It is assumed that firms act within competitive environments. No collusion between them is allowed. Governments, taking their welfare functions under consideration, may choose a cooperative or non-cooperative version of the game. In other words, first, governments decide upon tariffs, taking into account the Cournot-type competitive reaction of firms. Then, the latter choose their optimal output.

The subject of the analysis is the situation of tariff rate bargaining between two countries $\mathrm{A}$ and $\mathrm{B}$. To make it simpler, it has been assumed that country A is an exclusive producer of the good, whose only consumers live in country B. The quantity of these goods will be denoted by $q_{a}$. On the other hand, the goods exclusively produced by country B will be bought by customers in country A $\left(q_{b}\right)$. This situation is nearly the same as double bilateral monopoly.

The demand functions of countries B and A are expressed by the following respective equations:

$$
\begin{aligned}
& p_{a}\left(q_{a}\right)=\alpha-q_{a}, \\
& p_{b}\left(q_{b}\right)=\alpha-q_{b},
\end{aligned}
$$

where:

$p_{a}$ - price of goods consumed in country A,

$p_{b}$ - price of goods consumed in country B, and

$a$ - positive constant ${ }^{1}$.

The number of suppliers on both markets varies from one to infinity. According to Shubik's extension of the Cournot model for $\mathrm{n}$ firms and a closed economy, the profit function of one of them is as follows (Shubik,1991, 102-106):

$$
\pi_{i}\left(q_{i}, q_{d}\right)=\left[p\left(q_{d}\right)-v\right] q_{i}-f c_{i},
$$

where

$\pi_{i}$-profit of firm $i$,

$q_{i}-$ quantity sold by the firm $i$,

$q_{d}-$ quantity sold on the market,

$p\left(q_{d}\right)$-market price,

$v$-unit variable cost equal among firms, and

$f c_{i}$-fixed cost of firm $i$.

The introduction of international trade exchange with customs tariffs changes the profit functions of exporters:

where:

$$
\begin{aligned}
& \pi_{a i}\left(q_{a i}, q_{a}\right)=\left[p_{a}\left(q_{a}\right)\left(1-D_{b}\right)-v\right] q_{a i}-f c_{i} \\
& \pi_{b i}\left(q_{b i}, q_{b}\right)=\left[p_{b}\left(q_{b}\right)\left(1-D_{a}\right)-v\right] q_{b i}-f c_{i}
\end{aligned}
$$

$D_{a}$ - custom duty in country $\mathrm{A}$,

\footnotetext{
${ }^{1}$ Hence, the size of the market and price elasticity of demand are not the researched factors, and for simplification of the model, the same slopes of the demand curves (equal 1) were assumed.
} 
$D_{b}$ - custom duty in country B.

The optimal quantity supplied by the exporter from economy A must fulfil the following equation:

$$
\frac{\partial \pi_{a i}\left(q_{a i}\right)}{\partial q_{a i}}=\frac{\partial p_{a}\left(q_{a}\right)}{\partial q_{a i}}\left(1-D_{b}\right) q_{a i}+p_{a}\left(q_{a}\right)\left(1-D_{b}\right)-v=0 .
$$

Substituting the right side of equation (3) for the demand function. Next we assume that $q_{a}=n_{a} q_{a 1}$ (where $n$ is the number of firms in the industry, and $q_{a 1}=\cdots=q_{a n}$ ). Thus, one may derive the optimal quantity supplied by the enterprise $i$ exporting to market $\mathrm{B}$ and the total quantity supplied:

$$
q_{a i}\left(D_{b}\right)=\frac{\alpha\left(1-D_{b}\right)-v}{\left(n_{a}+1\right)\left(1-D_{b}\right)}, \quad q_{a e}\left(D_{b}\right)=\frac{n_{a}\left(\alpha\left(1-D_{b}\right)-v\right)}{\left(n_{a}+1\right)\left(1-D_{b}\right)} .
$$

Formula (8) shows that the higher the number of firms, the higher the quantity in equilibrium, and the higher the customs tariff, the lower the quantity. Introducing equilibrium quantity $q_{a e}$ to the demand function, we can obtain the formula for the market price:

$$
p_{a e}\left(D_{b}\right)=\alpha-\frac{n_{a}\left(\alpha\left(1-D_{b}\right)-v\right)}{\left(n_{a}+1\right)\left(1-D_{b}\right)} .
$$

The functions for economy $\mathrm{B}$ are analogous. All are dependent on the tariffs.

The welfare functions for both economies consist of three components. They differ by the essence and the subject benefiting from foreign exchange. However, each of these components can be expressed as a function, depending on the level of the country's own and partner's tariff rates. The components of the benefit function are the consumer's surplus realized on imported goods, producer's surplus realized by exporting companies, and budget income from import customs duties.

The consumer's surplus has been set, according to its graphic interpretation, as the area between the demand curve and the equilibrium price's horizontal line for the good's quantity from zero to the equilibrium point (Boulding, 1945, 853). Hence, it is expressed for the consumers from country A by the following formula:

$$
C S_{a}\left(q_{b e}\right)=\frac{1}{2}\left(\alpha-p_{b}\left(q_{b e}\right)\right) q_{b e} .
$$

Substituting the market price and the quantity demanded with the right sides of equations (8) and (9), we get the consumer surplus in country $\mathrm{A}$ as a function of the tariff rate of country A:

$$
C S_{a}\left(D_{a}\right)=\frac{1}{2}\left(\frac{n_{b}\left(\alpha\left(1-D_{a}\right)-v\right)}{\left(n_{b}+1\right)\left(1-D_{a}\right)}\right)^{2} .
$$

The producer's surplus is the profit achieved by companies. The aggregated profit of all exporting companies can be expressed by the following equation:

where

$$
\pi_{a e}\left(q_{a e}\right)=\left(\left(1-D_{b}\right) p_{a}\left(q_{a e}\right)-v\right) q_{a e}-F C,
$$

$F C$ - aggregated fixed cost of exporting firms from country A.

By introducing the left sides of equations (8) and (9), we get the producer surplus of exporters from country $\mathrm{A}$ as a function of the tariff rate in economy $\mathrm{B}$ :

$$
\pi_{a e}\left(D_{b}\right)=\frac{n_{a}\left(\alpha\left(1-D_{b}\right)-v\right)^{2}}{\left(n_{a}+1\right)^{2}\left(1-D_{b}\right)}-F C .
$$

The third component of economy A's welfare function is the budget revenue from customs duties:

$$
D R_{a}\left(q_{b e}\right)=D_{a} p_{b}\left(q_{b e}\right) q_{b e} .
$$

The $D R_{a}$ function may also be expressed as follows:

$$
D R_{a}\left(D_{a}\right)=\frac{D_{a} n_{b}\left(\alpha\left(1-D_{a}\right)-v\right)\left(\alpha\left(1-D_{a}\right)+n_{b} v\right)}{\left(n_{b}+1\right)^{2}\left(1-D_{a}\right)^{2}}
$$

Eventually, we have all the components to present the welfare function of economy A:

$$
U_{a}\left(D_{a}, D_{b}\right)=\frac{n_{a}\left(\alpha\left(1-D_{b}\right)-v\right)^{2}}{\left(n_{a}+1\right)^{2}\left(1-D_{b}\right)}-F C+\frac{1}{2}\left(\frac{n_{b}\left(\alpha\left(1-D_{a}\right)-v\right)}{\left(n_{b}+1\right)\left(1-D_{a}\right)}\right)^{2}+\frac{D_{a} n_{b}\left(\alpha\left(1-D_{a}\right)-v\right)\left(\alpha\left(1-D_{a}\right)+n_{b} v\right)}{\left(n_{b}+1\right)^{2}\left(1-D_{a}\right)^{2}}
$$

and for economy $\mathrm{B}$ : 


$$
U_{b}\left(D_{a}, D_{b}\right)=\frac{n_{b}\left(\alpha\left(1-D_{a}\right)-v\right)^{2}}{\left(n_{b}+1\right)^{2}\left(1-D_{a}\right)}-F C+\frac{1}{2}\left(\frac{n_{a}\left(\alpha\left(1-D_{b}\right)-v\right)}{\left(n_{a}+1\right)\left(1-D_{b}\right)}\right)^{2}+\frac{D_{b} n_{a}\left(\alpha\left(1-D_{b}\right)-v\right)\left(\alpha\left(1-D_{b}\right)+n_{a} v\right)}{\left(n_{a}+1\right)^{2}\left(1-D_{b}\right)^{2}} .
$$

Both functions have two independent variables: one's own and partner's tariff rate. It constitutes the environment of a strategic game between entities trying to maximize benefits. The game can be solved either by non-cooperative Nash equilibrium or by the cooperative solution indicated by one of the bargaining schemes.

\section{DETERMINATION OF NON-COOPERATIVE AND COOPERATIVE SOLUTIONS}

The research was performed for the version of the model defined by the parameters $a=100, v=20$, and $F C=300$. The numbers of firms on both markets taken into account were one (monopoly), five (oligopoly), and 100 (close enough to a competitive market ${ }^{2}$ ). The payoff matrices were developed for the tariff rates for the range $0 \%-60 \%$, in order to capture the Nash equilibrium for all versions of the model. There are six of them, all of which are presented in the Table 1.

Table 1

Market structures in economies A and B

\begin{tabular}{|c|c|c|c|c|c|c|}
\hline Number of versions & 1 & 2 & 3 & 4 & 5 & 6 \\
\hline$n_{a}$ & 1 & 5 & 100 & 1 & 1 & 5 \\
\hline$n_{b}$ & 1 & 5 & 100 & 5 & 100 & 100 \\
\hline
\end{tabular}

Source: own study.

The first three versions of the model based on the symmetric market concentration were chosen to investigate the impact of the number of firms on the tariff rates in non-cooperative and cooperative mode of the game. Variants 4-6 were designed to reveal the consequences of asymmetry of the market concentration. The study method will be presented for version 4 .

Table 2

Payoff matrix of economy A

\begin{tabular}{|c|c|c|c|c|c|c|c|c|c|c|c|c|}
\hline & \multicolumn{11}{|c|}{ Tariff rate in economy $\mathrm{A}-D_{a}$} \\
\hline & & $0 \%$ & $6 \%$ & $12 \%$ & $18 \%$ & $24 \%$ & $30 \%$ & $36 \%$ & $42 \%$ & $48 \%$ & $54 \%$ & $60 \%$ \\
\hline \multirow{11}{*}{ 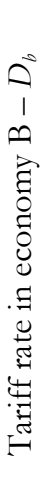 } & $0 \%$ & 3522 & 3587 & 3648 & 3705 & 3754 & 3794 & 3822 & 3832 & 3814 & 3755 & 3626 \\
\hline & $6 \%$ & 3379 & 3444 & 3505 & 3561 & 3610 & 3651 & 3678 & 3688 & 3671 & 3611 & 3483 \\
\hline & $12 \%$ & 3236 & 3301 & 3362 & 3418 & 3468 & 3508 & 3536 & 3545 & 3528 & 3468 & 3340 \\
\hline & $18 \%$ & 3094 & 3159 & 3220 & 3277 & 3326 & 3366 & 3394 & 3404 & 3386 & 3327 & 3198 \\
\hline & $24 \%$ & 2954 & 3019 & 3080 & 3136 & 3186 & 3226 & 3254 & 3263 & 3246 & 3186 & 3058 \\
\hline & $30 \%$ & 2815 & 2880 & 2941 & 2997 & 3047 & 3087 & 3115 & 3124 & 3107 & 3048 & 2919 \\
\hline & $36 \%$ & 2678 & 2744 & 2805 & 2861 & 2910 & 2951 & 2978 & 2988 & 2970 & 2911 & 2783 \\
\hline & $42 \%$ & 2545 & 2610 & 2671 & 2727 & 2776 & 2817 & 2844 & 2854 & 2837 & 2777 & 2649 \\
\hline & $48 \%$ & 2415 & 2480 & 2541 & 2597 & 2646 & 2687 & 2714 & 2724 & 2706 & 2647 & 2519 \\
\hline & $54 \%$ & 2290 & 2355 & 2416 & 2472 & 2521 & 2562 & 2589 & 2599 & 2582 & 2522 & 2394 \\
\hline & $60 \%$ & 2172 & 2237 & 2298 & 2355 & 2404 & 2444 & 2472 & 2482 & 2464 & 2405 & 2276 \\
\hline
\end{tabular}

Source: own study.

\footnotetext{
${ }^{2}$ Increasing the number of firms on both markets from 100 to 1000 decreases the market price only by $4.1 \%$.
} 
Payoff matrices express the strategic advantage of market A. Consumers on this market benefit from competition among exporters from economy B. Monopolization of the good A supply causes a higher profit for the sole exporter. However, revenues from customs duty payments of economy B are higher for lower tariff rates; the inverse is true for tariffs higher than $20 \%$.

Table 3

Payoff matrix of economy $\mathrm{B}$

\begin{tabular}{|c|c|c|c|c|c|c|c|c|c|c|c|c|}
\hline & \multicolumn{11}{|c|}{ Tariff rate in economy $\mathrm{A}-D_{a}$} \\
\hline & & $0 \%$ & $6 \%$ & $12 \%$ & $18 \%$ & $24 \%$ & $30 \%$ & $36 \%$ & $42 \%$ & $48 \%$ & $54 \%$ & $60 \%$ \\
\hline \multirow{11}{*}{ 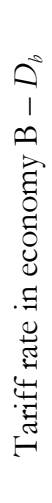 } & $0 \%$ & 1389 & 1309 & 1230 & 1151 & 1073 & 996 & 920 & 846 & 774 & 704 & 639 \\
\hline & $6 \%$ & 1507 & 1427 & 1348 & 1269 & 1191 & 1114 & 1038 & 964 & 891 & 822 & 757 \\
\hline & $12 \%$ & 1620 & 1540 & 1461 & 1382 & 1304 & 1227 & 1151 & 1077 & 1004 & 935 & 870 \\
\hline & $18 \%$ & 1727 & 1647 & 1568 & 1489 & 1411 & 1334 & 1258 & 1184 & 1111 & 1042 & 977 \\
\hline & $24 \%$ & 1826 & 1746 & 1667 & 1588 & 1510 & 1433 & 1357 & 1283 & 1211 & 1141 & 1076 \\
\hline & $30 \%$ & 1915 & 1836 & 1756 & 1678 & 1600 & 1523 & 1447 & 1372 & 1300 & 1231 & 1165 \\
\hline & $36 \%$ & 1992 & 1912 & 1833 & 1754 & 1676 & 1599 & 1523 & 1449 & 1376 & 1307 & 1242 \\
\hline & $42 \%$ & 2051 & 1971 & 1892 & 1813 & 1735 & 1658 & 1582 & 1507 & 1435 & 1366 & 1301 \\
\hline & $48 \%$ & 2085 & 2005 & 1926 & 1847 & 1769 & 1692 & 1616 & 1542 & 1469 & 1400 & 1335 \\
\hline & $54 \%$ & 2083 & 2003 & 1924 & 1845 & 1767 & 1690 & 1614 & 1540 & 1468 & 1398 & 1333 \\
\hline & $60 \%$ & 2026 & 1947 & 1867 & 1789 & 1711 & 1634 & 1558 & 1483 & 1411 & 1342 & 1276 \\
\hline
\end{tabular}

Source: own study.

Nash equilibrium was indicated by the pair of strategies that fulfilled the following conditions:

$$
\begin{aligned}
\frac{\partial U_{a}\left(D_{a}, D_{b}\right)}{\partial D_{a}} & =\frac{n_{b}^{2} v^{2}}{\left(n_{b}+1\right)^{2}\left(1-D_{a}\right)^{3}}-\frac{n_{b}^{2} \alpha v}{\left(n_{b}+1\right)^{2}\left(1-D_{a}\right)^{2}}+\frac{n_{b} \alpha^{2}}{\left(n_{b}+1\right)^{2}}+\left(\frac{2 \alpha v n_{b}^{2}}{\left(n_{b}+1\right)^{2}}-\frac{\alpha n_{b} v}{\left(n_{b}+1\right)}\right) \frac{1}{\left(1-D_{a}\right)^{2}}- \\
\frac{n_{b}^{2} v^{2}\left(1+D_{a}\right)}{\left(n_{b}+1\right)^{2}\left(1-D_{a}\right)^{3}} & =0 \\
\frac{\partial U_{b}\left(D_{a}, D_{b}\right)}{\partial D_{b}} & =\frac{n_{a}^{2} v^{2}}{\left(n_{a}+1\right)^{2}\left(1-D_{b}\right)^{3}}-\frac{n_{a}^{2} \alpha v}{\left(n_{a}+1\right)^{2}\left(1-D_{b}\right)^{2}}+\frac{n_{a} \alpha^{2}}{\left(n_{a}+1\right)^{2}}+\left(\frac{2 \alpha v n_{a}^{2}}{\left(n_{a}+1\right)^{2}}-\frac{\alpha n_{a} v}{\left(n_{a}+1\right)}\right) \frac{1}{\left(1-D_{b}\right)^{2}}- \\
\frac{n_{a}^{2} v^{2}\left(1+D_{b}\right)}{\left(n_{a}+1\right)^{2}\left(1-D_{b}\right)^{3}} & =0 .
\end{aligned}
$$

Assuming $D_{a} \neq 100 \%$, we can solve equation (18) and obtain the following cubic equation:

$$
\frac{\partial U_{a}\left(D_{a}, D_{b}\right)}{\partial D_{a}}=\alpha\left(1-D_{a}\right)^{3}-v\left(1-D_{a}\right)-\frac{n_{b} v^{2}}{\alpha} D_{a}=0 .
$$

Introducing $x=1-D_{a}$ and dividing both sides by $a \neq 0$, we can obtain the canonical version:

$$
x^{3}+\left(\frac{n_{b} v^{2}}{\alpha^{2}}-\frac{v}{\alpha}\right) x-\frac{n_{b} v^{2}}{\alpha^{2}}=0 .
$$

Using Cardano's method, we can achieve the general function indicating the optimal (in a Nash equilibrium sense) level of tariff in country A for every number of firms in the exporting industry in country B:

$$
D_{a}\left(n_{b}\right)=1-\sqrt[3]{\frac{n_{b} v^{2}}{2 \alpha^{2}}+\sqrt{\frac{n_{b}^{2} v^{4}}{4 \alpha^{4}}+\left(\frac{n_{b} v^{2}}{3 \alpha^{2}}-\frac{v}{3 \alpha}\right)^{3}}}-\sqrt[3]{\frac{n_{b} v^{2}}{2 \alpha^{2}}-\sqrt{\frac{n_{b}^{2} v^{4}}{4 \alpha^{4}}+\left(\frac{n_{b} v^{2}}{3 \alpha^{2}}-\frac{v}{3 \alpha}\right)^{3}}}
$$




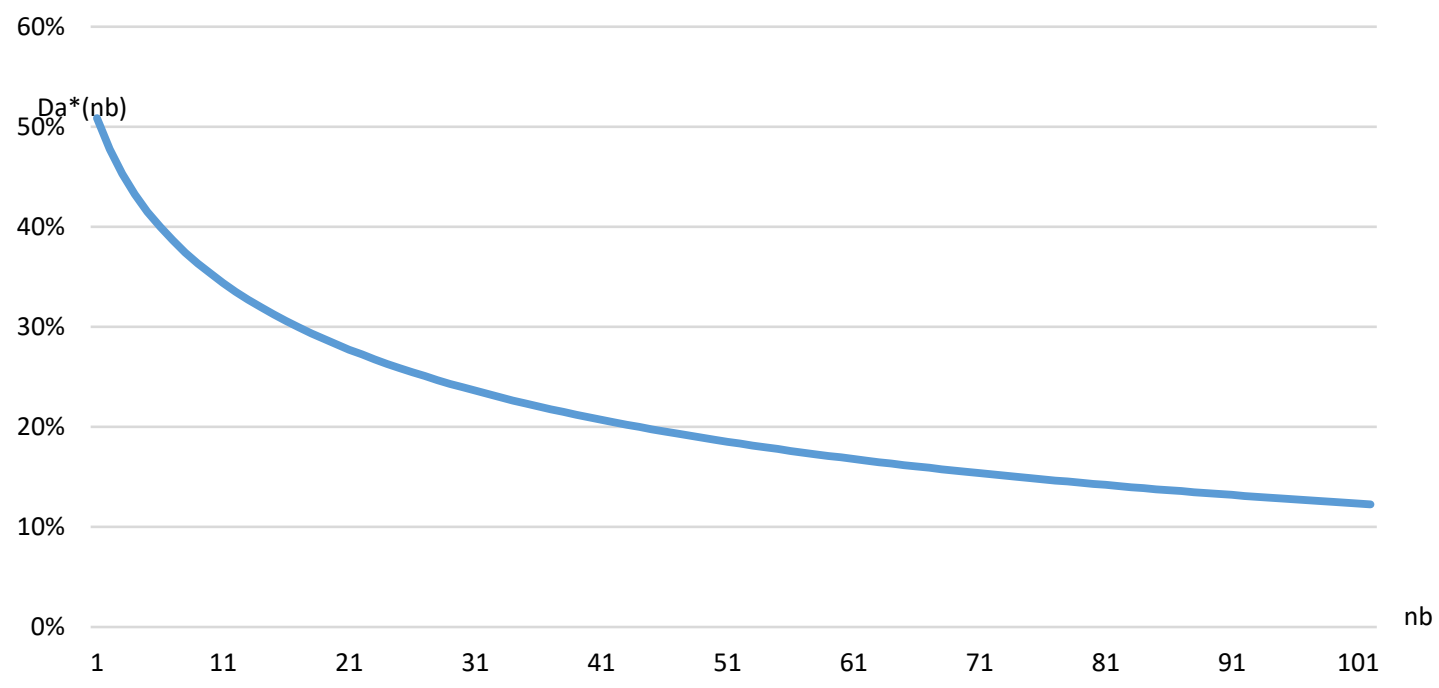

Graph 1. Nash equilibria $\mathrm{Da}^{*}$ maximizing welfare as a function of the number of exporters $\mathrm{nb}$ Source: own study.

As $n_{b} \rightarrow \infty$, the function goes asymptotically to zero. The optimal level of tariff for perfect competition is $D_{a *}=0 \%$. Function (22) shows that a higher tariff is the reaction for a higher market concentration on the exporter's side.

Searching deeper, we can check how welfare behaves in the wake of a growing number of exporters. Let us presume that $n_{a}=n_{b}$. By inserting welfare maximizing tariffs on both sides, we can obtain the maximum welfare function given the number of exporting firms.

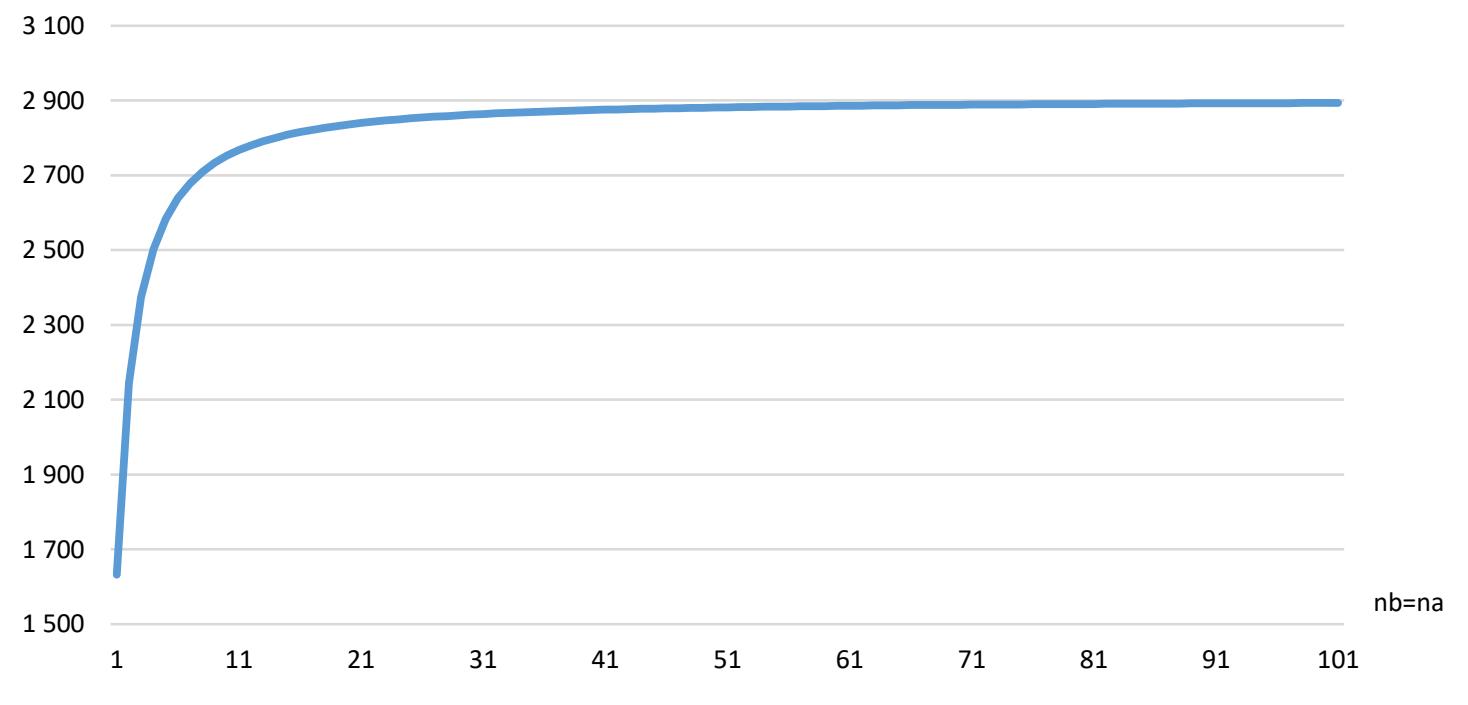

Graph 2. Welfare in Nash equilibria given the number of exporters equal in both countries Source: own study.

The graph shows that the welfare grows rapidly for a small number of firms. Then, marginal welfare starts shrinking. One may say that growth of the competition in industries with more than 50 firms generates almost irrelevant welfare increases. 
In terms of version $4\left(n_{a}=1, n_{b}=5\right)$, equations (18) and (19) respectively stand for $D_{a}=41.5 \%$ and $D_{b}=50.9 \%{ }^{3}$. This pair of strategies $(\mathrm{NE})$ produces the outcome $U_{a}\left(D_{a}, D_{b}\right)=2663.5$ and $U_{b}\left(D_{a}, D_{b}\right)=1552.1$. These strategies dominate all other tariff rates in both economies. Decision makers choose them, regardless of the opponent's choice. The optimal tariff rate joins two tendencies. The growing level of one's own tariff diminishes consumer surplus and increases national budget revenues. The strategy from NE makes the sum of CS and DR maximal.

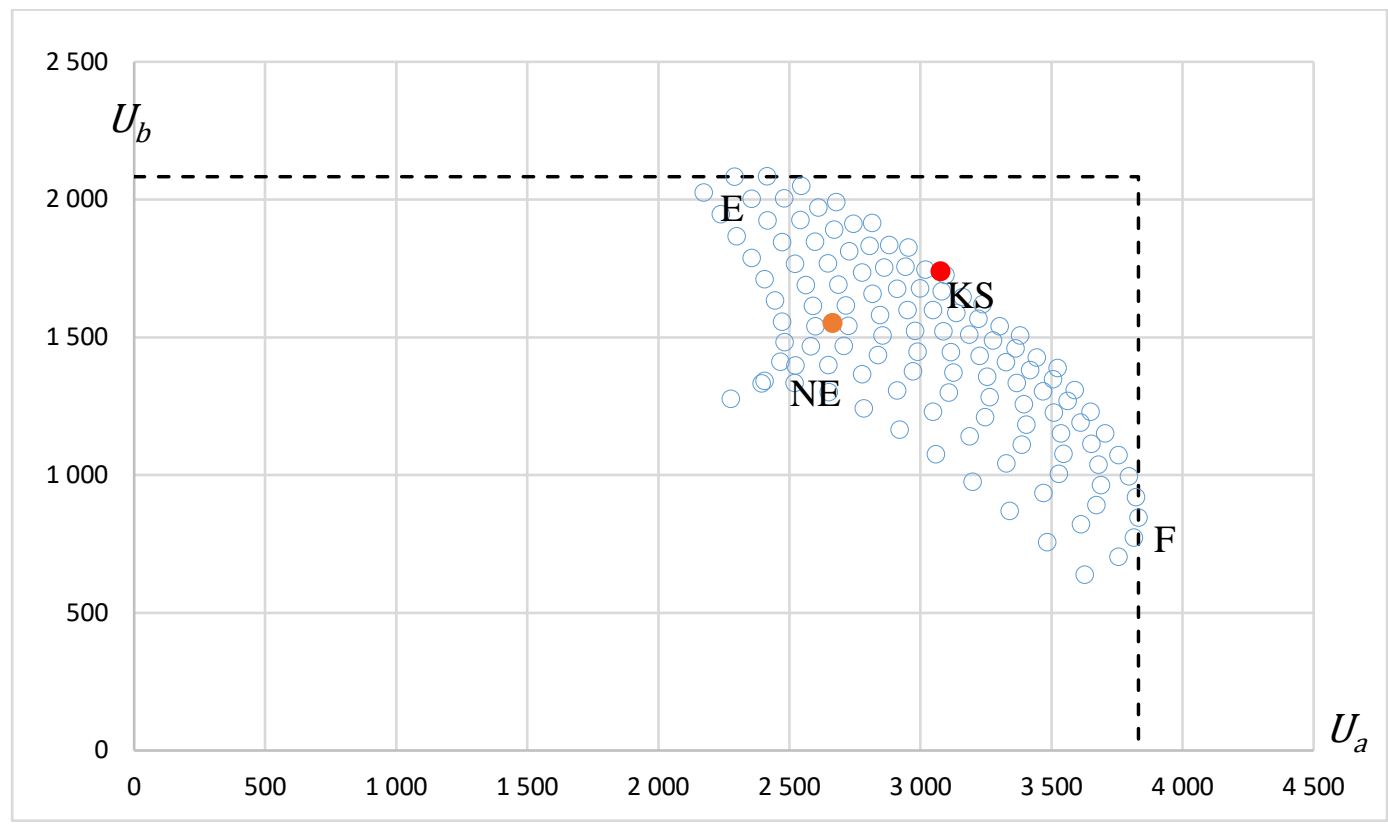

Graph 3. Welfare of economies A and B - version $4(n a=1, n b=5)$

Source: own study.

Tariff rates are mostly the subject of negotiations, which represents the cooperative mode of the presented game. The outcome of the negotiations may be entrusted to one of the bargaining solutions. There are several methods for indicating this. Two of the most eminent are the Nash bargaining solution (1950, 1953) and Kalai-Smorodinsky bargaining scheme (1975). This choice is supported by the results of W. Thomson's research (1994). He performed rigorous tests of nine bargaining solutions. The criteria were dominance of the middle point, independence from the utility scales, monotonicity of the negotiation set changes, and vulnerability to the uncertainty towards the shape of this set. The tests were passed the best by the Nash bargaining solution, Kalai-Smorodinsky bargaining scheme, and egalitarian solution. For the purpose of this study, the Kalai-Smorodinsky bargaining solution was chosen (Kalai, Smorodinsky 1975). Mostly because it was founded on the critique of Nash's independence of irrelevant alternatives axiom

All bargaining schemes search for solutions within the Pareto optimal set. One may view it on graph 3 as the north-east border of the bargaining set between points $\mathrm{E}$ and $\mathrm{F}$. In the proposed model, all the points of the Pareto optimal set are the outcome of the zero tariff rate chosen by either player A or player B, including the mutual choice of a tariff equal to zero. The strategy chosen by player A produces Pareto optimal outcomes more beneficiary for player B, and vice versa.

The crucial component of every bargaining solution is the indication of the status quo point. Nash proposed the point of optimal threats, which is used to persuade players to find the cooperative solution

\footnotetext{
${ }^{3}$ In Table 2 and 3, Nash equilibria are marked for $D_{a}=42 \%$ and $D_{b}=48 \%$ because the taken tariff rate change was $6 \%$.
} 
and sustain it (1953). An alternative proposal is the mutual choice of the prudential strategy, in which players can "shelter" in the case of negotiation failure (Straffin 1993, 69). The dominance of Nash equilibrium (NE) strategies over all alternatives makes this point a stable prudential solution, which was presumed to be the status quo point. The same selection of the status quo point is performed quite often (e.g., Harrison, Radstrom 1991, 431). The most important meaning of the status quo is the understanding of this point as the reference measure of the bargaining solution fairness.

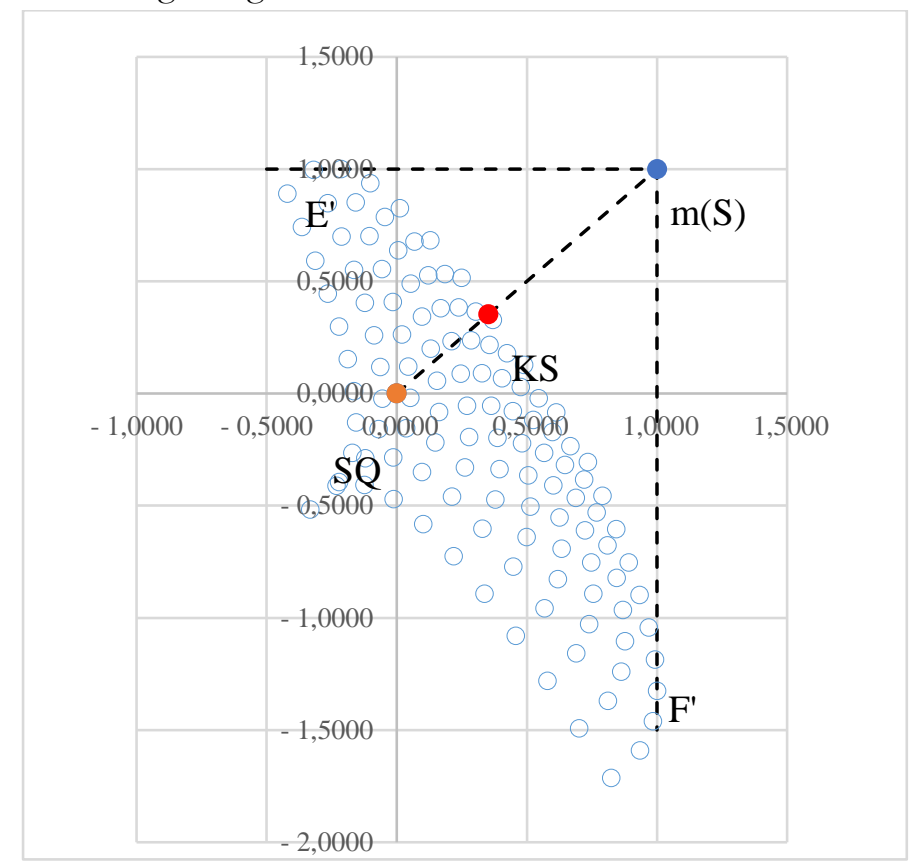

Graph 4. Kalai-Smorodinsky bargaining solution for $n_{a}=1$ and $n_{b}=5$

Source: own study.

The Kalai-Smorodinsky bargaining solution demands the linear transformation of the bargaining set. First, the utilities of both players are reduced by the value of the game in the status quo point. The operation moves the bargaining set, placing the status quo in the point $(0 ; 0)$. Then, the reduced welfare values of each plyer are divided by their maximal values, respectively, in order scale them within the range $\langle 0 ; 1\rangle$. Following this, the bargaining set is bordered by the horizontal and vertical lines coming out from the point $\mathrm{m}(\mathrm{S})$, with coordinates $(1 ; 1)$, joining the maximal utilities of both parties (graph 4).

According to the Kalai-Smorodinsky solution, the cooperative result of the game lies on the intersection of the Pareto optimal set and the line joining the status quo (SQ) and $\mathrm{m}(\mathrm{S})$ points. Hence, the KS solution can be estimated by finding the outcome where linearly transformed Pareto optimal utilities for both players equalize. This is fulfilled for the pair of strategies $\left(D_{a}=0 \%, D_{b}=18.8 \%\right)$ that produces linearly transformed utilities $U_{a t}=U_{b t}=0.353$. By transforming the utilities linearly backwards, we get $U_{a}\left(D_{a}, D_{b}\right)=$ 3075.8 and $U_{b}\left(D_{a}, D_{b}\right)=1740.1$. By agreeing upon the cooperation and accepting the Kalai-Smorodinsky bargaining solution with the status quo in the NE point, both players increase their benefits significantly. The status quo point gives them, respectively, $U_{a}\left(D_{a}, D_{b}\right)=2663.5$ and $U_{b}\left(D_{a}, D_{b}\right)=1552.1$. It is worth mentioning that the game is the prisoner's dilemma type with non-Pareto optimal Nash equilibrium and the Pareto optimal solution remaining under the threat of treason.

The methodology described above was applied for all six chosen versions of the model. The results are presented in Table 4. The first three symmetric versions can be distinguished by three features. First, the cooperative solution is constantly a zero tariff option. Entirely liberated trade is a cooperative solution 
for evenly concentrated markets. One should remember that these solutions remain under the threat of breaking the cooperation by one of the players choosing the Nash equilibrium strategy. The immediate optimal response of the other leads to a stable Nash equilibrium point. The second feature of the symmetric market structures deals with Nash equilibria. The growing level of competition produces diminishing tariff rates. A growing level of economic freedom on the exporting market leads to the liberalization of international trade. The third feature is general; the marginal benefit from growing competition on the market is diminishing.

Table 4

Nash equilibria and cooperative solutions for all six versions of the model.

\begin{tabular}{|c|c|c|c|c|c|c|c|c|c|c|c|c|}
\hline & \multicolumn{2}{|c|}{$n_{a}=n_{b}=1$} & \multicolumn{2}{|c|}{$n_{a}=n_{b}=5$} & \multicolumn{2}{|c|}{$n_{a}=n_{b}=100$} & \multicolumn{2}{|c|}{$n_{a}=1, n_{b}=5$} & \multicolumn{2}{|c|}{$n_{a}=1, n_{b}=100$} & \multicolumn{2}{|c|}{$n_{a}=5, n_{b}=100$} \\
\hline & $\mathrm{NE}$ & KS & $\mathrm{NE}$ & KS & $\mathrm{NE}$ & KS & $\mathrm{NE}$ & KS & $\mathrm{NE}$ & KS & $\mathrm{NE}$ & KS \\
\hline$D_{a}$ & $50.9 \%$ & $0.0 \%$ & $41.5 \%$ & $0.0 \%$ & $12.4 \%$ & $0.0 \%$ & $41.5 \%$ & $0.0 \%$ & $12.4 \%$ & $0.0 \%$ & $12.4 \%$ & $0.0 \%$ \\
\hline$D_{b}$ & $50.9 \%$ & $0.0 \%$ & $41.5 \%$ & $0.0 \%$ & $12.4 \%$ & $0.0 \%$ & $50.9 \%$ & $18.8 \%$ & $50.9 \%$ & $46.3 \%$ & $41.5 \%$ & $35.8 \%$ \\
\hline$q_{a e}$ & 29.6 & 40.0 & 54.8 & 66.7 & 76.4 & 79.2 & 29.6 & 37.7 & 29.6 & 31.4 & 54.8 & 57.4 \\
\hline$q_{b e}$ & 29.6 & 40.0 & 54.8 & 66.7 & 76.4 & 79.2 & 54.8 & 66.7 & 76.4 & 79.2 & 76.4 & 79.2 \\
\hline$p_{a e}$ & 70.4 & 60.0 & 45.2 & 33.3 & 23.6 & 20.8 & 70.4 & 62.3 & 70.4 & 68.6 & 45.2 & 42.6 \\
\hline$p_{b e}$ & 70.4 & 60.0 & 45.2 & 33.3 & 23.6 & 20.8 & 45.2 & 33.3 & 23.6 & 20.8 & 23.6 & 20.8 \\
\hline$\pi_{a e}\left(D_{b}\right)$ & 131.9 & 1300.0 & 51.7 & 588.9 & -248.9 & -237.3 & 131.9 & 853.6 & 131.9 & 228.7 & 51.7 & 122.3 \\
\hline$\pi_{b e}\left(D_{a}\right)$ & 131.9 & 1300.0 & 51.7 & 588.9 & -248.9 & -237.3 & 51.7 & 588.9 & -248.9 & -237.3 & -248.9 & -237.3 \\
\hline$C S_{a}\left(D_{a}\right)$ & 439.5 & 800.0 & 1503.4 & 2222.2 & 2918.5 & 3136.9 & 1503.4 & 2222.2 & 2918.5 & 3136.9 & 2918.5 & 3136.9 \\
\hline$C S_{b}\left(D_{b}\right)$ & 439.5 & 800.0 & 1503.4 & 2222.2 & 2918.5 & 3136.9 & 439.5 & 710.2 & 439.5 & 492.3 & 1503.4 & 1645.2 \\
\hline$D^{D R_{a}}\left(D_{a}\right)$ & 1061.0 & 0.0 & 1028.3 & 0.0 & 223.9 & 0.0 & 1028.3 & 0.0 & 223.9 & 0.0 & 223.9 & 0.0 \\
\hline$D R_{b}\left(D_{b}\right)$ & \begin{tabular}{|l|}
1061.0 \\
\end{tabular} & 0.0 & 1028.3 & 0.0 & 223.9 & 0.0 & 1061.0 & 441.1 & 1061.0 & 997.0 & 1028.3 & 876.2 \\
\hline$U_{a}\left(D_{a}, D_{b}\right)$ & 1632.3 & 2100.0 & 2583.3 & 2811.1 & 2893.5 & 2899.7 & 2663.5 & 3075.8 & 3274.3 & 3365.6 & 3194.1 & 3259.3 \\
\hline$U_{b}\left(D_{a}, D_{b}\right)$ & 1632.3 & 2100.0 & 2583.3 & 2811.1 & 2893.5 & 2899.7 & 1552.1 & 1740.1 & 1251.6 & 1252.0 & 2282.8 & 2284.2 \\
\hline
\end{tabular}

Source: own study.

Asymmetric versions of the model show that the level of the tariff rate for a particular economy depends on the concentration on the other market. The more monopolized the exporters' market is, the higher the tariff rate protecting the importing market is. This stands for both a cooperative and noncooperative solution. Once again, growing competition on the exporting market leads to the liberalization of international trade. The asymmetric version of the cooperative solution is a zero tariff option only for more monopolized markets. Economies importing from more concentrated markets should negotiate tariffs higher than zero. The higher the difference between the number of firms, the higher this negotiated tariff should be in the KS solution.

\section{CONCLUSIONS}

The purpose of this article was to investigate the influence of the exporter's market structure on the level of optimal tariff rates. The goal function was the welfare defined as the sum of the consumer and producer surpluses and the customs revenues. In terms of a non-cooperative game, the optimal tariff rate is the monotonically decreasing function of the number of firms in the exporting industry. Therefore, the hypothesis of growing competition which stimulates free trade obtained significant support. This conclusion supports the results of simulations showing diminishing optimal tariff rates of country $\mathrm{A}$ in the wake of a growing number of exporters from country B (Zotti, Lucke 2014).

The possibility of estimating tariff rates maximizing the welfare for both countries opens the way for deriving the function of maximum welfare given the number of firms, presuming symmetric market 
structures. The result was quite interesting. Significant welfare growth is available for a limited number of firms. From a foreign trade point of view, the reduction of industry concentration is irrelevant above a certain level of competition.

Non-cooperative equilibrium welfares can be increased by switching to the cooperative version of the game and taking the Pareto optimal solution indicated by the Kalai-Smorodinsky methodology. For symmetric market structures, a zero tariff is the choice for either country A or country B. In these cases (versions 1-3), there is regularity. The more monopolized the markets are, the higher the benefit from cooperation. Countries with competitive markets are less interested in trade negotiations and building free trade areas.

For asymmetric market structures (versions 4-6), the chosen bargaining solution is a zero tariff for the country importing from a more competitive market and reduced from the NE point tariff, but higher than zero for another country. The stronger asymmetry is, the higher this tariff is. Trade negotiations are a political issue. It may be unacceptable for some governments to agree on a tariff higher than zero inflicted by the trade partner and zero tariff for them. It is a very serious barrier in trade negotiations because agreeing on tariffs mutually reduced to zero is less welfare-providing than Nash equilibrium for countries with more competitive markets.

\section{REFERENCES}

Bhagwati, J. (1965). On the equivalence of tariffs and quotas. Trade, growth and the balance of payments, 53-67.

Boulding, K. E. (1945). The concept of economic surplus. The American Economic Review, 35(5), 851-869.

Copeland, B. R. (1990). Strategic interaction among nations: negotiable and non-negotiable trade barriers. Canadian Journal of Economics, 84-108.

Dixit, A., \& Norman, V. (1980). Theory of international trade: A dual, general equilibrium approach. Cambridge University Press.

Ederington, J. (2003). Policy linkage and uncertainty in international agreements. Economic Inquiry, 41(2), 305-317.

Ethier, W. J. (1982). National and international returns to scale in the modern theory of international trade. The American Economic Review, 72(3), 389-405.

Harrison, G. W., \& Rutström, E. E. (1991). Trade wars, trade negotiations and applied game theory. The Economic Journal, 101(406), 420-435.

Kalai, E., \& Smorodinsky, M. (1975). Other solutions to Nash's bargaining problem. Econometrica: Journal of the Econometric Society, 513-518.

Krishna, K. (1984). 985. Trade Restrictions as Facilitating Practices.". Harvard Institute of Economic Research, 251-70.

Krugman, P. R. (1979). Increasing returns, monopolistic competition, and international trade. Journal of international Economics, 9(4), 469-479.

Nash Jr, J. F. (1950). The bargaining problem. Econometrica: Journal of the econometric society, 155-162.

Nash, J.F. (1953). Two-Person Cooperative Games. Econometrica, 21, 128-140.

Nash, J. (1951). Non-cooperative games. Annals of mathematics, 286-295.

Shubik, M. (1991). A Game-theoretic Approach to Political Economy, fourth printing.

Straffin, P. D. (1993). Game Theory and Strategy, Math. Association of America, Washington, DC.

Zhang, J., L. Xue, L. Zu (2013). Farsighted free trade networks, International Journal of Game Theory, 42, 375-398.

Zotti, J., \& Lucke, B. (2014). Welfare-optimal trade and competition policies in small open oligopolistic economies. The Journal of International Trade \& Economic Development, 23(3), 402-423. 